Sports Coaching

\title{
Monitoring of overtraining and motivation in elite soccer players
}

\author{
Leonardo Henrique Silva Fagundes ${ }^{1}$ (D), Israel Teoldo da $\operatorname{Costa}^{2}$ (D), Cleiton Pereira Reis ${ }^{1}$ (D), \\ Guilherme de Sousa Pinheiro ${ }^{3}$ (D), Varley Teoldo Costa $^{1}$ \\ ${ }^{1}$ Universidade Federal de Minas Gerais, Departamento de Ciências do Esporte, Laboratório de \\ Psicologia do Esporte, UFMG Soccer Science Center, Belo Horizonte, MG, Brazil; ${ }^{2}$ Universidade \\ Federal de Viçosa, Núcleo de Pesquisa e Estudos em Futebol, Laboratório de Psicologia do \\ Esporte, Viçosa, MG, Brazil; ${ }^{3}$ Technische Universität München, Fakultät für Sport und \\ Gesundheitswissenschaften, Lehrstuhl für Trainingswissenschaft und Sportinformatik, München, \\ Deutschland.
}

\author{
Associate Editor: Ricardo Barbieri, Estácio UniSEB, Ribeirão Preto, SP, Brasil
}

\begin{abstract}
Aim: This study aimed to monitor the behavior of the overtraining and motivations dimensions, as well as to verify whether these dimensions correlate in the preparatory and competitive periods over the season. Methods: Professional soccer players $(\mathrm{n}=32)$ answered the Stress and Recovery Questionnaire for Athletes (RESTQ-Sport 76) and the Sport Motivation Scale (SMS) during the preparatory and competitive periods. Results: Intrinsic amotivation and sport-specific recovery were lower in the competitive period than in the preparatory period. In the preseason, motivation presented a strong and negative correlation with overall recovery $\left(p=0.001 ; r=-0.75 ; r^{2}=0.56\right)$ and sport-specific recovery $\left(p=0.001 ; r=-0.72 ; r^{2}=0.52\right.$ ). The amotivation explained in $56 \%$ the variance of the results of the overall recovery and $52 \%$ of the sport-specific recovery. During the competitive phase, amotivation showed a strong and positive correlation with overall stress $\left(p=0.001 ; r=0.70 ; r^{2}=0.49\right)$ and sport-specific stress $(p=0.001 ; r=0.79$; $\left.r^{2}=0.62\right)$. The amotivation accounted for $49 \%$ of the variance in the results of the overall stress and $62 \%$ of sport-specific stress in soccer players. Conclusion: There are associations between overtraining and motivation during the investigated periods. Through longitudinal monitoring in professional soccer, it was verified that the dimensions of amotivation, overall recovery, and sport-specific stress could be related to the prevention symptoms of overtraining in a professional soccer team.
\end{abstract}

Keywords: professional soccer, athletes, RESTQ-Sport 76, motivation, football.

\section{Introduction}

In soccer, the purpose of athletic planning is to appropriately manage the training load to optimize sports performance ${ }^{1}$ through a process of planning, monitoring, and load adjustment. Effective training loads are among the key issues for coaches and players ${ }^{2}$. Sports preparation is usually divided into two phases: the preparatory and competitive period. The first one, commonly referred to as preseason, is designed to develop players' physical and psychological capacities and prepare them for the various demands of the whole season ${ }^{3}$. The second, competitive season refers to the time at which soccer teams compete during the year, maintaining training routines. This phase is characterized by different performance states of players due to the application of different training loads that affect the stress-recovery status of each player ${ }^{4}$. Particularly during the competitive season, it is important to achieve an adequate balance between training and recovery to ensure optimal physical preparation ${ }^{5}$.
Throughout the sports season, professional teams from the elite of Brazilian soccer (1st division) train and compete in approximately 11 months ${ }^{4}$. A team can participate in more than 65 official matches per year ${ }^{6}$. Soccer players need to attain multiple physical training goals within similar periods and a competitive fixture schedule that requires multiple peaks across many months. These individuals experience a significant cognitive demand in a match $^{7}$. Studies indicate that competing at a high level with potentially congested playing schedules may increase psychological demands ${ }^{8}$, cause perceptual disturbances ${ }^{9}$, affect sleep quality levels ${ }^{5,10}$ and can lead to match-related fatigue ${ }^{11}$. In addition, players are under high pressure for results by managers, coaching staff, teammates, family, friends, fans, and the media ${ }^{12}$. The sum of all these variables reported above can compromise the physical and mental health of players ${ }^{13}$ as well as influence the behavior of the dimensions of overtraining and motivation in professional soccer. 
During a typical training cycle, players often undergo periods of overload and recovery in an attempt to optimize physical performance. The imbalance between stress and recovery periods, with continuously high training loads and insufficient recovery, may cause accumulated fatigue, resulting in long-term reductions in performance capacity ${ }^{12,14}$. This maladaptation to training can manifest as a state of non-functional overreaching and, in extreme and prolonged cases, may develop into the overtraining syndrome ${ }^{15}$. The player may present a drop in performance associated with intense fatigue that may or may not be related to other biological, psychological and social symptoms ${ }^{16-18}$. Overtraining is defined as longerterm decrements in performance with or without a range of other symptoms (e.g., hormonal dysregulation, reduced immune function and sleep disorders) that can last from weeks to months to recover and restore performance in the sport $^{14,15}$.

The motivation can be explained through the theory of self-determination ${ }^{19-21}$. According to this theory, the behavior of an individual is established along a motivational continuum by levels of self-determination, which results in three different types of motivation: amotivation, extrinsic and intrinsic motivation ${ }^{22-24}$. Intrinsic motivation is related to personal factors linked to pleasure and satisfaction generated by the sport itself without expecting rewards external to the activity. Extrinsic motivation is associated with external environmental factors linked to rewards from good performance. Amotivation is characterized by a feeling of hopelessness in which intrinsic or extrinsic motivation does not affect the player's performance. The player feels no reason to continue practicing the sport, which can generate feelings of frustration and consequently compromise sport performance ${ }^{21,23}$.

Many previous studies have investigated the overtraining phenomenon ${ }^{15,25}$. Lemyre et al. ${ }^{26}$ found that elite players with signs of overtraining had lower motivational values. They concluded that both variables could contribute to predicting burnout at the end of the competitive period. Brink et al. ${ }^{27}$ and Meeusen et al. ${ }^{15}$ identified that players with signs of overtraining showed a drop in performance. Previous research has found alterations in mental health well-being ${ }^{28}$. Nevertheless, few studies have evaluated the overtraining and motivational levels throughout the whole sports season in elite players ${ }^{26}$.

Motivation in soccer has been associated with technical-tactical skills. Souza Filho et al. ${ }^{29}$ identified that the lower the playing time of a player during the competitive period, the higher his amotivation. Thus, situations experienced by the player, such as being scheduled for a match and not playing, as well as not being listed for the match, can start the amotivation process. Other psychological constructs have been investigated, such as commitment ${ }^{30}$, and burnout ${ }^{26}$. The results show that players with overtraining are more likely to decrease their commitment to the sport and increase the chances of burnout in the sports season. In this way, the players with overtraining present low levels of intrinsic motivation ${ }^{26}$ and it influences the interest, satisfaction, and pleasure of the soccer player for the practice of the sport ${ }^{30}$.

In view of the evidence mentioned above, this study hypothesizes that the higher the levels of intrinsic motivation, the less likely the soccer player is to experience symptoms of overtraining. In the elite sport, motivation, especially intrinsic motivation, may act as a protective variable to mitigate the risks of overtraining ${ }^{26}$. However, little is known about the process of interaction between these two variables in professional soccer. Therefore, this study aimed to monitor the behavior of the overtraining and motivations dimensions, as well as to verify whether these dimensions correlate in the preparatory and competitive periods over the season.

\section{Methods}

\section{Participants}

Thirty-two Brazilian professional soccer players from the same team participated in this study (age: 24.16 \pm 4.58 years old; professional experience: $4.82 \pm 4.64$ years). These players participated in the competitions organized by the Brazilian Soccer Confederation (CBF): State Championship, Brazil Cup, and Brazilian Championship (First division). All the players participated in a total of 7 evaluations, with 2 in the preparatory period and 5 in the competitive period.

This study was approved by the Ethics and Research Committee of the Universidade Federal de Minas Gerais (CAAE: 38900914.0.0000.5149). The players involved in the study signed an informed consent form agreeing to participate in the study.

\section{Measures}

Recovery-stress questionnaire for athletes (RESTQ-Sport 76)

The questionnaire (RESTQ-Sport 76), developed by Kellmann and Kallus ${ }^{31}$ and validated in Portuguese for Brazilian players by Costa and Samulski ${ }^{32}$, is composed of 76 items organized into 19 scales, with 12 general scales and 7 scales specific to sports. Each item is answered on a Likert scale, ranging from 0 (never), 1 (seldom), 2 (sometimes), 3 (often), 4 (more often), 5 (very often) until 6 (always) and should be completed based on the occurrence of events and activities reported in the past $72 \mathrm{~h}^{33}$.

The RESTQ-Sport 76 consists of a series of statements. These statements possibly describe his psychic or physical well-being or his activities during the past few days and nights. The players must select the answer that most accurately reflects their thoughts and activities. Indicate how often each statement was right in his case in the past days. The related statements should refer to perfor- 
mance during training and competition. Thus, some examples of items would be: "In the past (3) days/nights ... my body felt strong" (for the scale Being in Shape) or "In the past (3) days/nights ... I was overtired" (for the scale Fatigue).

According to the method used in the previous studies ${ }^{4,12}$ with the same psychometric instrument, the 19 scales were grouped into 4 major dimensions: overall stress, sport-specific stress, overall recovery, and sportspecific recovery. The RESTQ-Sport 76 internal consistency index ( $\alpha$ by Cronbach) for this sample was overall stress $(\alpha=0.93)$, sport-specific stress $(\alpha=0.86)$, overall recovery $(\alpha=0.85)$ and sport-specific recovery $(\alpha=0.92)$.

\section{Sport Motivation Scale (SMS)}

The questionnaire SMS, developed by Pelletier et al. ${ }^{24}$ and validated in Portuguese for Brazilian soccer players by Costa et al. ${ }^{23}$, is composed of 28 items distributed in 7 scales. According to the method of previous studies with the same psychometric instrument, the scales were grouped into 3 large dimensions, as follows: intrinsic motivation, extrinsic motivation, and amotivation ${ }^{26}$.

In SMS, each item is answered from the perception of the player's motivation, based on a Likert scale of 7 points, varying from $1-2$ (does not correspond at all), 3 $-4-5$ (correspond moderately), and $6-7$ (corresponds exactly). Players should use the scales mentioned above and indicate to what extent each of the following items corresponds to one of the reasons for which he is presently practicing his sport. The question used in the questionnaire is "Why do you practice your sport?" Thus, examples of items would be "For the pleasure I feel in living exciting experiences" (for the scale Intrinsic Motivation) or "I don't know anymore; I have the impression that I am incapable of succeeding in this sport" (for the scale Amotivation). The internal consistency indices ( $\alpha$ by Cronbach) of the SMS for this study were intrinsic motivation $(\alpha=0.95)$, extrinsic motivation $(\alpha=0.92)$ and amotivation $(\alpha=0.85)$.

\section{Procedures}

After the authorization of the club officers, a schedule was drawn up with previously stipulated dates according to the official matches of the team. The players individually answered the questionnaires (RESTQSport 76 and SMS) at 7 moments over the season concerning the preparatory and competitive periods. On evaluation days, all players received verbal instructions from the researcher and answered the questionnaires in the afternoon, between 2:00 and 3:00 pm, before initiating the training session of the day. Evaluations 1 and 2 were carried out at the beginning and end of the preparatory period, respectively. During this same period, soccer players did not participate in official matches. On the competitive period, evaluations $3,4,5,6$, and 7 were held $24 \mathrm{~h}$ before each official match.

The data from each collection of the same period were grouped, as recommended in another study with the same variables ${ }^{26,27}$. A comparative analysis was performed between each collection from the preparatory period (e.g., $1 \times 2$ ) and later from the competitive period (e.g., $3 \times 4,3 \times 5,3 \times 6,3 \times 7 \ldots$ ). All analyses were performed separately to assess whether a particular collection session could interfere with the results of the others. No significant differences were found between the collections of each of the two periods. Thus, due to the non-existence of such differences, the data of each of the periods were grouped to characterize the preparatory period (average of the results of evaluations 1 and 2) and competitive period (average of the results of evaluations $3,4,5,6$, and 7 ).

\section{Statistical analysis}

The internal consistency of the instruments was verified by means of Alfa de Cronbach ( $\alpha$ ). For all analyses established in this study, the Shapiro-Wilk normality test was used. The data did not show a normal distribution. The descriptive statistics were composed of the median and interquartile range (Q1 - Q3).

To verify differences between the dimensions of the RESTQ-Sport 76 and SMS in the different moments over the season Friedman test was used, later the Wilcoxon test was performed to identify if differences occurred between the two investigated periods. The effect size (ES) analysis of the Mann-Whitney test was calculated using the equation: $r=Z / \sqrt{ } N,(r=\mathrm{ES}, Z=\mathrm{z}$-score, and $N=$ overall number of cases $)^{34}$. Based on the recommendations of Cohen $^{35}$, ES was classified as small $(0.1<\mathrm{ES}<0.3)$, medium $(0.3<\mathrm{ES}<0.5)$ and large $(\mathrm{ES} \geq 0.5)$.

The Spearman test was used to investigate correlations of the dimensions of overtraining and motivation in the preparatory and competitive periods. The correlations were classified according to the coefficients: no correlation $(r<0.20)$, weak $(>0.20 r<0.45)$, moderate $(>0.45 r$ $<0.70)$ and strong $(r \geq 0.70)^{36}$. The correlation coefficient $(r)$ has been associated with another coefficient, called the coefficient of determination $\left(r^{2}\right)$. The coefficient of determination is interpreted as the proportion of the total variation of the dependent variable that is explained by the variation of the independent variable ${ }^{34}$. That is, it indicates the proportion (\%) of variation in $y$ that is explained by the variation in $x$ and vice versa; thus, if $r=0.50$, then $r^{2}=0.25$, if $r=.70, r^{2}=0.49$ and so on. The data were analyzed using the Statistical Package for the Social Sciences (IBM Corp. Released 2011. IBM SPSS Statistics for Windows, version 20.0. Armonk, NY: IBM Corp.). The statistical significance was set at $p<0.001$. 


\section{Result}

Overtraining and motivation of players in the preparatory and competitive periods

Table 1 shows the values of the dimensions of overtraining and motivation of players in the preparatory and competitive periods. The Wilcoxon test was performed, and significant differences were found in the dimensions of sport-specific recovery $(p=0.030 ; \mathrm{ES}=-0.272)$ and intrinsic motivation ( $p=0.001$; ES $=-0.320)$. The evaluation magnitude of the differences found in these comparisons indicates, respectively, the small and medium effect size for these two investigated dimensions. The other dimensions have remained stable throughout the sports season.

\section{Overtraining and motivation in the preparatory period during the sports season}

Table 2 presents the analyses between the dimensions of overtraining and motivation in the preparatory period during the sports season. It was found that amotivation presented a strong and negative correlation with overall recovery $(r=-0.75 ; p=0.001)$ and with sportspecific recovery $(r=-0.72 ; p=0.001)$. Nevertheless, in the same period, amotivation presented a moderate and positive correlation with sport-specific stress $(r=0.50$; $p=0.004)$.

\section{Overtraining and players' motivation in the competitive period}

Table 3 presents the correlations between overtraining and players' motivation in the competitive period. Amotivation showed a strong and positive correlation with overall stress $(r=.70 ; p=0.001)$ and sport-specific stress $(r=0.79 ; p=0.001)$. In addition, amotivation showed a moderate and negative correlation with overall recovery $(r=-0.61 ; p=0.001)$ and sport-specific recovery $(r=-0.64 ; p=0.001)$.
Table 2 - Correlation between the dimensions of overtraining and motivation in the preparatory period.

\begin{tabular}{|c|c|c|c|c|c|c|}
\hline \multirow[t]{2}{*}{ Dimensions } & \multicolumn{2}{|c|}{$\begin{array}{l}\text { Intrinsic moti- } \\
\text { vation }\end{array}$} & \multicolumn{2}{|c|}{$\begin{array}{c}\text { Extrinsic } \\
\text { motivation }\end{array}$} & \multicolumn{2}{|c|}{ Amotivation } \\
\hline & $r$ & $r^{2}$ & $r$ & $r^{2}$ & $r$ & $r^{2}$ \\
\hline Overall stress & -0.10 & 0.01 & 0.20 & 0.04 & 0.31 & 0.09 \\
\hline Sport-specific stress & 0.04 & 0.00 & 0.21 & 0.04 & $0.50 *$ & 0.25 \\
\hline Overall recovery & 0.33 & 0.11 & 0.12 & 0.01 & $-0.75^{*}$ & 0.56 \\
\hline Sport-specific recovery & 0.35 & 0.12 & 0.10 & 0.01 & $-0.72 *$ & 0.53 \\
\hline
\end{tabular}

Table 3 - Correlation between the dimensions of overtraining and motivation in the competitive period.

\begin{tabular}{|c|c|c|c|c|c|c|}
\hline \multirow[t]{2}{*}{ Dimensions } & \multicolumn{2}{|c|}{$\begin{array}{c}\text { Intrinsic } \\
\text { motivation }\end{array}$} & \multicolumn{2}{|c|}{$\begin{array}{c}\text { Extrinsic } \\
\text { motivation }\end{array}$} & \multicolumn{2}{|c|}{ Amotivation } \\
\hline & $r$ & $r^{2}$ & $r$ & $r^{2}$ & $r$ & $r^{2}$ \\
\hline Overall stress & -0.10 & 0.01 & 0.38 & 0.14 & $0.70^{*}$ & 0.49 \\
\hline Sport-specific stress & 0.05 & 0.00 & 0.37 & 0.13 & $0.79 *$ & 0.62 \\
\hline Overall recovery & 0.35 & 0.12 & 0.05 & 0.00 & $-0.61 *$ & 0.37 \\
\hline Sport-specific recovery & 0.30 & 0.09 & -0.10 & 0.01 & $-.064 *$ & 0.41 \\
\hline
\end{tabular}

\section{Discussion}

This study aimed to monitor the behavior of the dimensions of overtraining and motivation and verify whether these dimensions correlate in the preparatory and competitive periods of a sports season. In relation to monitoring the behavior of the dimensions of overtraining and motivation in this study (see Table 1), it is observed that only two dimensions (sport-specific recovery and intrinsic motivation) have had statistically significant changes in soccer players over the season.

When analyzing overtraining separately, only the sport-specific recovery dimension decreased in the competitive period to the detriment of the values presented in the preparatory period. This dimension is linked to the

Table 1 - Comparison of overtraining and players' motivation between the preparatory and competitive periods.

\begin{tabular}{|c|c|c|c|c|c|c|}
\hline Dimensions & $\begin{array}{c}\text { Preparatory } \\
\text { Mdn (Q1-Q3) }\end{array}$ & $\begin{array}{l}\text { Competitive } \\
\text { Mdn (Q1-Q3) }\end{array}$ & $\mathbf{Z}$ & $\boldsymbol{P}$ & ES & INT \\
\hline Overall stress & $1.40(1.02-1.86)$ & $1.40(0.95-1.84)$ & -0.370 & 0.711 & -0.046 & small \\
\hline Sport-specific stress & $1.44(0.96-1.78)$ & $1.45(0.85-1.96)$ & -0.892 & 0.373 & -0.111 & small \\
\hline Overall recovery & $4.10(3.63-4.41)$ & $3.94(3.41-4.37)$ & -1.646 & 0.100 & -0.206 & small \\
\hline Sport-specific recovery & $4.11(3.64-4.69)$ & $4.08(3.34-4.55)$ & -2.176 & $0.030^{*}$ & -0.272 & small \\
\hline Intrinsic motivation & $5.41(4.56-5.91)$ & $5.24(4.26-5.66)$ & -2.553 & $0.001^{*}$ & -0.320 & medium \\
\hline Extrinsic motivation & $4.04(3.33-4.53)$ & $3.83(3.05-4.68)$ & -1.449 & 0.147 & -0.181 & small \\
\hline Amotivation & $1.20(1.00-1.75)$ & $1.36(1.01-2.58)$ & -1.184 & 0.236 & -0.148 & small \\
\hline
\end{tabular}

Note Q1 (upper quartile), Q3 (lower quartile), ES (effect size), INT (interpretation of ES according to Cohen ${ }^{35}$ ). ${ }^{*} p<0.001$. 
specific recovery factors in sports that occur continuously with the objective of re-establishing the psychological, physiological and social aspects of the player ${ }^{15}$. Sportspecific recovery is an intentional and planned process to provide the best possible conditions to cope in a balanced way with the demands coming from various stressful stimuli coming from sport ${ }^{14,16}$. Efficient recovery methods should optimize psychophysical processes and increase their psychological and physiological reserves to achieve high performance in the competitive period ${ }^{12,25}$. It was found that the soccer players in this study decreased their perception about their sport-specific recovery and consequently about the aspects that compose this dimension as the feeling of being in shape, personal accomplishment, and their levels of self-efficacy and self-regulation. Losses linked to both overall recovery and sport-specific recovery can lead the player to amotivation processes ${ }^{26}$ and overtraining ${ }^{15,27}$.

The manifestations of the sport-specific recovery dimension are characterized by the four subscales mentioned above (being in shape, personal accomplishment, self-efficacy, and self-regulation). These subscales are associated with factors that the player describes, such as the sensation of feeling good physically, with vitality, feeling integrated into the team, and using his mental skills in his preparation, boosting the pursuit of objectives. It is also especially associated with his motivation throughout the sports season ${ }^{16,32}$. In this study, in the preparatory period, sport-specific recovery was more latent in relation to the competitive period. This can be explained by the fact that, in the preseason, players do not play official matches. During this period, the players train daily, and this process is better controlled by the coaching staff, which monitors and adjusts the workloads according to the previously planned periodization ${ }^{1,2}$. In addition, during this period, soccer players participated in base camps, where they are allowed to feed and sleep better, favoring the state of overcompensation ${ }^{10,15}$. Studies indicate that improving the recovery processes in the players' routine may favor sports performance and prevent mental fatigue, as well as the injuries and illnesses arising from the imbalance of the training loads, matches, and recovery time ${ }^{12,14}$. It is usually observed an improvement in player sports performance after a recovery period ${ }^{17}$.

It should be noted that intrinsic motivation (IM) and extrinsic motivation (EM) are important principles for understanding motivational processes ${ }^{20-22}$. When interpreting the psychological constructs of motivation, it is observed that two of the three dimensions that measure the motivational aspects in soccer players had a constant behavior over the season. Only the IM showed statistically lower values in the competitive period compared to the preparatory period. This dimension is characterized by three sub-scales (IM to know, IM to accomplish things, and IM to experience stimulation). These scales are asso- ciated with intrinsic factors that lead the individual to remain internally motivated to practice sport ${ }^{23,24,29}$.

The most autonomous form of motivation is intrinsic motivation, which occurs when players derive a sense of enjoyment and satisfaction from participating in sports ${ }^{30}$. The player's intrinsic motivation is related to his voluntary participation in sports practice, with the apparent absence of rewards or external pressure ${ }^{19,20}$. The evaluated players present a greater perception of personal factors related to the search for comprehension, new competencies, and even soccer-related skills. The preparatory period in the season, the period for preparing players before competitions, are moments when players dedicate themselves to improving their psychological, physical, technical and tactical skills ${ }^{4}$. These skills will be used later in matches during the sports season ${ }^{17,18}$. The preseason contains several new activities proposed by the coaching staff, which causes a perception in players of sports development and growth. The practice training in this period may stimulate experiences that allow the sensations of excitement, pleasure and enjoyment ${ }^{19,30}$. This also makes the training sessions more attractive and pleasurable, which directly affects the levels of intrinsic motivation of players.

Extrinsic motivation involves participation that is contingent upon specific rewards or outcomes. Amotivation poses that there are no linkages between the individual's actions and outcomes of these actions ${ }^{23}$. Individuals with amotivation do not value an activity, do not feel competent to perform it, and based on experience believe that they cannot control the outcomes ${ }^{20,37}$. Regarding these aspects, it was observed that these dimensions remained stable during the sports season. One of the possible explanations of the study is the fact that the sample is composed of professional players who are paid by the clubs and see soccer as a job. Moreover, some individuals are extrinsically motivated to avoid criticism ${ }^{37}$. Only the internal motivational factors tend to present oscillations since they are closely linked to the players' performance or not in matches during the competitive period of the season ${ }^{29}$. Therefore, monitoring sport-specific recovery and intrinsic motivation in the preparatory period may be important for the coaching staff since both dimensions relate positively to the player's psychophysiological well-being and contribute to high sporting performance in soccer.

This study also aimed to verify the existence of correlations between overtraining and motivation during the two periods (preparatory and competitive) of the sports season. When analyzing the correlations in the preparatory period (see Table 2), it was observed that the association of amotivation with overall recovery and sport-specific recovery is more evident in the preparatory period than the competitive period. It was found that amotivation was able to explain in $56 \%$ the variation in the results of overall recovery and $52 \%$ of the sport-specific recovery in the preparatory period. When recovery levels increase, amoti- 
vation levels decrease because of its negative ratio at this stage of the sports season. The strong correlation found between the dimensions of amotivation and overall recovery and sport-specific recovery in this study allowed us to observe whether amotivation would be able to influence the recovery of soccer players. In this sense, the results showed that the greater the recovery of a player during the preparatory period, the lower the probability of players being amotivated. In addition, players with low levels of amotivation tend to achieve a better-quality recovery during this period.

The results presented corroborate the hypothesis of this study, since the dimension of intrinsic motivation maintained high levels over the two periods investigated. This behavior acted as a protective variable regarding risky behaviors ${ }^{37}$, such as minimizing the risks of overtraining ${ }^{15,26}$.

In Brazilian soccer, the preseason runs at the beginning of the year, after the soccer holidays (the period between December and January). It is well known that the motivational relationship influences sport performan$\mathrm{ce}^{19,29}$. Players who start the preseason and consequently the competitive year amotivated tend to recover inappropriately from the training sessions in which they are submitted, as well as presenting high levels of sport-specific stress compared to other players in the team. This study found a strong correlation between overtraining and motivation in Brazilian professional soccer players, especially correlations associating the dimension of amotivation with the dimensions of the overall stress and sport-specific stress.

Amotivation and overtraining are known to have a direct relationship ${ }^{26}$. Amotivated players are more susceptible to overtraining, and players in a state of overtraining have higher levels of amotivation in relation to the practice of their sport ${ }^{15}$. This type of problem appears both in the preparatory and competitive periods. In this way, there is evidence for professionals working in the preparation (psychological, physical, technical and tactical) of elite players in soccer that is necessary to monitor the players' motivation over the season. This variable may be a good marker to prevent overtraining through the number of training sessions and official matches in which these players are submitted in the year ${ }^{6,14}$.

According to Garcia-Mas et al. ${ }^{30}$, amotivation has a negative influence on sports practice and could affect the performance of soccer players during training and competitions. Therefore, it is known that the behavior of one dimension can negatively or positively influence that of the other dimension and that overtraining, and motivation are directly linked to high soccer performance ${ }^{17,18}$. When analyzing the correlations between overtraining and motivation in the competitive period (see Table 3), it was observed that amotivation was associated with all dimensions of stress and recovery.
From this perspective, studies have pointed out that when stress levels increase, amotivation levels also tend to increase due to the positive relationship between the two dimensions ${ }^{26}$. In this study with male professional soccer players, there was no association between overall stress with other dimensions in the preparatory period, but it was shown that in the competitive period, amotivation explained in $49 \%$ the variation in the results of overall stress. In the same period, amotivation accounted for $62 \%$ of the variance of sport-specific stress in the sports season. Moreover, throughout the competitions, the stress factors increase because, in addition to the training, there is competitiveness within the team by titularity, the interpersonal relationship between players and members of the coaching staff is intensified, and the demands for results become more frequent in the routine of the professional soccer player ${ }^{17}$. In elite professional sports, a very high traveling frequency is required to compete, and these subjects reduce their participation in social activities, diminishing their conviviality with family and friends $s^{9,10,18}$. In official matches, players face a high risk of injury ${ }^{3}$ and are judged by their performance on the field in each match. Therefore, even in the face of the adversities experienced by soccer players in their work routine, good interpersonal relationships, self-esteem, and adequate control of training loads favor and motivate players to achieve high sports performance ${ }^{17-19}$.

Finally, the correlations between the dimensions of overtraining and motivation were notorious in the two investigated periods. Amotivation was evidenced as it presented associations with the dimensions of stress and recovery in both periods. In the sports context, it is important to be aware of the player's mental health status ${ }^{28}$. Monitoring these variables can provide relevant information on the current psychophysiological state in which the soccer player finds himself and overtraining and amotivation can negatively impact the performance of professional soccer players.

The limitations of this study were to evaluate only one soccer team and the reduced contact time of researchers with professional players available by the coaching staff. Therefore, it was not possible to apply a wider battery of tests that could evaluate other psychological constructs. Despite this limitation, this study provides unique information on the behavior of overtraining and motivation of a Brazilian professional soccer team. Furthermore, the team presented a sporting performance that enabled the achievement of the objectives planned for the season. A total of 16 official matches were played in 3 different competitions (state and national levels). There were 6 wins, 7 draws, and 3 defeats, representing a success rate of $52 \%$. The sport results could influence levels of intrinsic motivation over the season. The findings of this study may help soccer professionals and sports scientists understand the impact of overtraining and motivation over the season 
and the relationship that exists between these two psychological constructs that directly interfere with players' performance.

\section{Conclusion}

The levels of sport-specific recovery and intrinsic motivation showed alterations throughout the sports season. Amotivation has been highlighted and explained the variations in the dimensions of overtraining in the investigated periods. In the context of professional soccer, the monitoring of psychological variables such as amotivation, overall recovery, and sport-specific stress could contribute to the prevention of overtraining symptoms.

\section{Acknowledgments}

The authors would like to thank the managers, team staff and players. This work was supported by the Fapemig (Fundação de Amparo à Pesquisa do Estado de Minas Gerais) and PRPq (PróReitoria de Pesquisa e Pós-Graduação da UFMG).

\section{References}

1. Perroni F, Fittipaldi S, Falcioni L, Ghizzoni L, Borrione P, Vetrano $\mathrm{M}$, et al. Effect of pre-season training phase on anthropometric, hormonal and fitness parameters in young soccer players. PloS one. 2019;14(11). https://doi.org/ 10.1371/journal.pone.0225471.

2. Pinheiro G, Quintão R, Custódio I, Casamichana D, Couto BP. Analysis of relationships between different training load monitoring tools in elite U-20 soccer. Hum Mov Special Issues. 2018;19(5):52-9. https://doi:10.5114/ hm.2018.81014.

3. Ekstrand J, Spreco A, Windt J, Khan KM. Are elite soccer teams' preseason training sessions associated with fewer in-season injuries? A 15-year analysis from the Union of European Football Associations (UEFA) elite club injury study. Am J Sports Med. 2020;48(3):723-9. https://doi.org/ $10.1177 / 0363546519899359$.

4. Fagundes LHS, Noce F, Albuquerque MR, Andrade AGP, Costa VT. Can motivation and overtraining predict burnout in professional soccer athletes in different periods of the season? Int J Sport Exerc Psychol. 2019;19(1):1-16. https:// doi.org/10.1080/1612197X.2019.1655778

5. Fullagar H, Skorski S, Duffield R, Meyer T. The effect of an acute sleep hygiene strategy following a late-night soccer match on recovery of players. Chronobiol Int. 2016;33 (5):490-505. https://doi:10.3109/07420528.2016.1149190.

6. Ernst \& Young. Impact of Brazilian Soccer [in portuguese] Confederação Brasileira de Futebol [Brazilian Football Confederation], 2019.

7. Gantois P, Caputo Ferreira ME, Lima-Junior D, Nakamura FY, Batista GR, Fonseca FS, et al. Effects of mental fatigue on passing decision-making performance in professional soccer athletes. Eur J Sport Sci. 2020;20(4):534-43. https:// doi:10.1080/17461391.2019.1656781.
8. Coutts AJ. Fatigue in football: it's not a brainless task! J Sports Sci. 2016;34(14):1296. https://doi.org/10.1080/ 02640414.2016.1170475.

9. Tofari PJ, Kemp JG, Cormack SJ. Measuring the response to simulated fixture congestion in soccer. Sci Med Football. 2020. https://doi.org/10.1080/24733938.2020.1746824.

10. Nédélec M, Halson S, Abaidia AE, Ahmaidi S, Dupont G. Stress, sleep, and recovery in elite soccer: A critical review of the literature. Sports Med. 2015;45(10):1387-400. https://doi:10.1007/s40279-015-0358-z.

11. Scott A, Malone J, Morgans R, Burgess D, Gregson W, Morton $\mathrm{J}$, et al. The relationship between physical match performance and 48-h post-game creatine kinase concentrations in English Premier League soccer players. Int J Sports Sci Coach. 2016;11(6):846-52. https://doi.org/ 10.1177/1747954116676111.

12. Heidari J, Beckmann J, Bertollo M, Brink M, Kallus W, Robazza C, et al. Multidimensional monitoring of recovery status and implications for performance. Int J Sports Physiol Perform. 2018;14(1):1-14. https://doi:10.1123/ ijspp.2017-0669. Epub ahead of print. PMID: 29543069.

13. Thompson CJ, Noon M, Towlson C, Perry J, Coutts AJ, Harper LD, et al. Understanding the presence of mental fatigue in English academy soccer players. J Sports Sci. 2020;1-7. https://doi.org/10.1080/02640414.2020.1746597.

14. Kellmann M, Bertollo M, Bosquet L, Brink M, Coutts AJ, Duffield R, et al. Recovery and Performance in Sport: Consensus Statement. Int J Sports Physiol Perform. 2018;13 (2):240-5. https://doi:10.1123/ijspp.2017-0759.

15. Meeusen R, Duclos M, Foster C, Fry A, Gleeson M, Nieman $\mathrm{D}$, et al. European College of Sport Science; American College of Sports Medicine. Prevention, diagnosis, and treatment of the overtraining syndrome: Joint Consensus Statement of the European College of Sport Science and the American College of Sports Medicine. Med Sci Sports Exerc. 2013;13(1):186-205. https://doi:10.1249/MSS.0b013e318279a10a. PMID: 23247672.

16. Kellmann M. Preventing overtraining in athletes in highintensity sports and stress/recovery monitoring. Scand J Med Sci Sports. 2010;20(2):95-102. https://doi:10.1111/ j.1600-0838.2010.01192.x.

17. Carling C, Lacome M, McCall A, Dupont G, Le Gall F, Simpson B, et al. Monitoring of post-match fatigue in professional soccer: Welcome to the real world. Sports Med. 2018;(48):1-8. http://doi.org/10.1007/s40279-018-0935-z.

18. Djaoui L, Haddad M, Chamaric K, Dellal A. Monitoring training load and fatigue in soccer players with physiological markers. Physiol Behav. 2017;(181):86-94. https://doi. org/10.1016/j.physbeh.2017.09.004.

19. Hendry DT, Crocker PRE, Williams AM, Hodges NJ. Tracking and comparing self-determined motivation in elite youth soccer: Influence of developmental activities, age, and skill. Front Psychol. 2019;(10):304. https:// doi:10.3389/fpsyg.2019.00304. PMID:52330890977.

20. Ryan RM, Deci EL. Self-determination theory: Basic psychological needs in motivation, development, and wellness. Guilford Press, 2017.

21. Sheldon KM, Osin EN, Gordeeva TO, Suchkov DD, Sychev OA. Evaluating the dimensionality of Self-Determination Theory's relative autonomy continuum. Pers Soc Psychol 
Bull. 2017;43(9);1215-38. https://doi.org/10.1177/ 0146167217711915.

22. Clancy RB, Herring MP, Campbell MJ. Motivation measures in sport: A critical review and bibliometric analysis. Front Psychol. 2017;(8):1-12. http://doi.org/10.3389/ fpsyg.2017.00348.

23. Costa VT, Albuquerque MR, Lopes M, Noce F, Costa IT, Ferreira R, et al. Validação da escala de motivação no esporte (SMS) no futebol para a língua portuguesa brasileira [Validation of the motivation scale in sport (SMS) in soccer for the portuguese language]. Rev Bras Educ Fís Esporte. 2011;25(3):537-46. http://doi.org/10.1590/S180755092011000300015.

24. Pelletier LG, Tuson DM, Fortier MS, Vallerand RJ, Brière NM, Blais MR. Toward a new measure of intrinsic motivation, extrinsic motivation and amotivation in sports: The Sport Motivation Scale. J Sport Exerc Psychol. 1995;17 (1):35-53. https://doi.org/10.1123/jsep.17.1.35.

25. Grandou C, Wallace L, Impellizzeri FM, Allen NG, Coutts AJ. Overtraining in resistance exercise: An exploratory systematic review and methodological appraisal of the literature. Sports Med. 2019;50(2). https://doi.org/10.1007/ s40279-019-01242-2.

26. Lemyre PN, Roberts GC, Stray-Gundersen J. Motivation, overtraining, and burnout: Can self-determined motivation predict overtraining and burnout in elite athletes? Eur J Sport Sci, 2007;7(2):115-26. https://doi.org/10.1080/ 17461390701302607.

27. Brink MS, Visscher C, Coutts AJ, Lemmink KA. Changes in perceived stress and recovery in overreached young elite soccer players. Scand J Med Sci Sports. 2010;22(2):28592. http://doi.org/10.1111/j.1600-0838.2010.01237.x.

28. Abbott W, Brownlee TE, Harper LD, Naughton RJ, Richardson A, Clifford T. A season-long investigation into the effects of injury, match selection, and training load on mental wellbeing in professional under 23 soccer players: A team case study. Eur J Sport Sci. 2019; 19(9):1250-6. http://doi.org/10.1080/17461391.2019.1600586.

29. Souza Filho MJ, Albuquerque MR, Costa IT, Malloy-Diniz LF, Costa VT. Comparison of the level of motivation of soccer athletes with high and low time played in matches of the U-20 category. Rev Educ Fís/UEM. 2018;29(1):1-10. https://doi.org/10.4025/jphyseduc.v29i1.2911.
30. Garcia-Mas A, Palou P, Gili M, Ponseti X, Borras PA, Vidal $\mathrm{J}$, et al. Commitment, enjoyment, and motivation in young soccer competitive players. Span J Psychol. 2010;13 (2):609-16. https://doi:10.1017/S1138741600002286.

31. Kellmann M, Kallus KW. The recovery-stress questionnaire for athletes: User manual. Human Kinetics, 2001;34-64.

32. Costa LOP, Samulski DM. Processo de validação do questionário de estresse e recuperação para atletas (RESTQSport 76) na língua portuguesa [Validation process of the recovery- stress questionnaire for athletes (RESTQ-Sport 76) in Portuguese]. Rev Bras Cie e Mov. 2005;13(1):79-86.

33. Kellmann M, Kallus KW, Samulski DM, Costa L, Simola R. Questionário de estresse e recuperação para atletas: Manual do usuário [Stress-Recovery Questionnaire for athletes: User manual]. 2009;5-84.

34. Field A. Discovering statistics using SPSS. London: SAGE Publications, 2009. Print.

35. Cohen J. Statistical Power Analysis. Current directions in psychological science. 1992;1(3):98-101. https:// doi:10.1111/1467-8721.ep10768783.

36. Fallowfield JL, Hale BJ, Wilkinson DM. Using Statistics in Sport and Exercise Science Research. Chichester, England: Lotus Pub, 2005. Print.

37. Komarc M, Harbichová I, Scheier LM. Psychometric validation of the Czech version of the Sport Motivation Scale. PLoS ONE. 2020;15(1). https://doi.org/10.1371/journalpone. 0227277 .

\section{Corresponding author}

Guilherme de Sousa Pinheiro. Technische Universität

München, München, Deutschland.

E-mail: guilherme.pinheiro@tum.de.

Manuscript received on December 10, 2020

Manuscript accepted on May 5, 2021

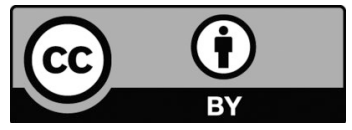

Motriz. The Journal of Physical Education. UNESP. Rio Claro, SP, Brazil - eISSN: 1980-6574 - under a license Creative Commons - Version 4.0 